\title{
EVALUASI EFEKTIVITAS DEKSAMETASON VERSUS PREDNISON UNTUK MENGURANGI EKSASERBASI DAN MENURUNKAN ANGKA RELAPS ASMA AKUT PADA ANAK DENGAN KAJIAN SYSTEMATIC REVIEW
}

\author{
Rolando Rahardjoputro ${ }^{1)}$, Erinda Nur Pratiwi ${ }^{2)}$, Inayatush Sholihah ${ }^{3)}$ \\ ${ }^{1,2}$ Fakultas Ilmu Kesehatan, Universitas Kusuma Husada Surakarta \\ ${ }^{3}$ Fakultas Matematika dan Ilmu Pengetahuan Alam, Universitas Sebelas Maret Surakarta \\ Email: rolando.r@ukh.ac.id
}

\begin{abstract}
ABSTRAK
Pengendalian kekambuhan asma dan kejadian relaps pada anak - anak merupakan salah satu poin penting dalam tatalaksana asma. Tujuan sistematik review ini adalah untuk mengetahui efektivitas penggunaan deksametason dibandingkan dengan prednison untuk mengurangi gejala eksaserbasi asma akut serta menurunkan angka relaps pada pasien anak-anak. Uji coba diperiksa berdasarkan kriteria inklusi dan eksklusi yang telah dirancang sebelumnya. Pada analisis Forest Plot didapatkan RR sebesar 0,97 pada perbandingan efektifitas prednison dengan deksametason untuk mengurangi gejala eksaserbasi asma akut pada anak - anak. RR sebesar 1,37 untuk perbandingan efektivitas dalam mengurangi kejadian relaps asma akut pada anak - anak. Dari 3 jurnal yang telah di bahas, didapatkan hasil tidak berbeda bermakna dari efektifitas deksametason dengan prednison dalam mengurangi gejala eksaserbasi asma akut pada anak - anak dan mengurangi kejadian relaps asma
\end{abstract}

Kata Kunci: Deksametason; Prednison; Kambuhan Astma; Anak - Anak

\begin{abstract}
Control of asthma exacerbation and relapse in children is one of the most important points in asthma therapy management. The aim of this systematic review is to determine the effectiveness of using dexamethasone compared with prednisone to reduce symptoms of acute asthma exacerbation and reduce relapse rates in pediatric patients. The trials were checked based on the inclusion and exclusion criteria that had been designed previously. In the Forest Plot analysis, an RR of 0.97 was found in the comparison of the effectiveness of prednisone with dexamethasone to reduce symptoms of acute asthma exacerbation in children. RR of 1.37 for comparison of effectiveness in reducing the incidence of acute asthma relapse in children. From the 3 journals obtained, the results were not significantly different for the effectiveness of dexamethasone compared with prednisone in reducing symptoms of acute asthma exacerbation in children and reducing the incidence of asthma relapses.
\end{abstract}

Keywords: Dexamethasone; Prednisone; Astma Exacerbation; Children

\section{PENDAHULUAN}

Asma adalah penyakit masa kanak-kanak kronis yang paling umum dan merupakan penyebab utama morbiditas terkait penyakit kronis, sebagaimana diukur dengan ketidakhadiran di sekolah, perawatan ke gawat darurat (ED), dan rawat inap. Eksaserbasi asma berjumlah hampir 5\% dari kunjungan ke Gawat Darurat, dan sekitar 15\% mungkin memerlukan pengobatan. Asma dapat menyerang pada berbagai usia, namun pada prinsipnya asma merupakan penyakit pediatri. Umumnya terjadi pada 5 tahun awal kehidupan dan 50 persen anak memiliki gejala asma sejak usia 2 tahun (Kelly \& Sorkness,2008).

Pengendalian terhadap eksaserbasi asma akut berpusat pada terapi bronkodilator serta penggunaan kortikosteroid untuk menekan level inflamasi. Beberapa penelitian telah membuktikan efikasi kortikosteroid dalam manajemen eksaserbasi asma akut.

Prednison / prednisolon oral adalah kortikosteroid yang digunakan, dua kali sehari selama 5 hari, karena waktu paruhnya adalah 1236 jam. Namun, rejimen pengobatan ini, mempunyai rasa pahit dan insidensi muntah yang dapat menyebabkan ketidakpatuhan, dengan suatu peningkatan risiko gejala persisten dan rawat inap. Sebaliknya, deksametason mempunyai keuntungan, karena waktu paruh biologinya lebih lama yaitu 36-72 jam dan merupakan pilihan yang lebih cocok.

Deksametason merupakan salah satu kortikosteroid yang paling banyak digunakan. 
Deksametason memiliki efek antiinflamasi dan imunosupresif poten (Nugroho, 2011).

Tujuan sistematik review ini adalah untuk mengetahui efektivitas penggunaan deksametason dibandingkan dengan prednison untuk mengurangi gejala eksaserbasi asma akut serta menurunkan angka relaps pada pasien anak-anak.

\section{METODE}

Pencarian secara elektronik dilakukan pada database PubMed dengan kata kunci "dexamethasone prednisone children asthma" dengan limitasi pada Randomized Controlled Trial, penelitian pada manusia dan berbahasa Inggris. Kami memasukkan penelitian yang randomized atau acak dengan kata kunci RCT karena mempunyai level of evidence yang cukup baik. Selain itu hanya penelitian pada anak-anak yang dimasukkan pada sistematik review ini.

Subyek dalam penelitian ini adalah anak - anak dengan umur 0 - 18 tahun yang mempunyai riwayat eksaserbasi asma. Intervensi penelitian ini yaitu pemberian dua macam obat kortikosteroid yaitu prednison atau deksametason untuk penanganan gejala eksaserbasi asma pada anak - anak. Rute pemberian baik melalui oral maupun parenteral tidak dimasukkan menjadi variabel dalam sistematik review ini. Luaran primer yang dinilai yaitu efektivitas pemberian deksametason atau prednison untuk mengurangi gejala eksaserbasi asma pada anak - anak yang terjadi beberapa jam / hari setelah penanganan serangan asma serta menurunkan angka relaps di Emergency Department.

Analisis statistik menggunakan perangkat software RevMan 5.3 yang didapatkan dari website Cochrane. Analisis statistik akan digunakan untuk menganalisis kumpulan data penelitian mengenai perbandingan efektivitas Deksametason dan Prednison dalam Forest Plot, sekaligus melihat heterogenitas data yang dianalisis.

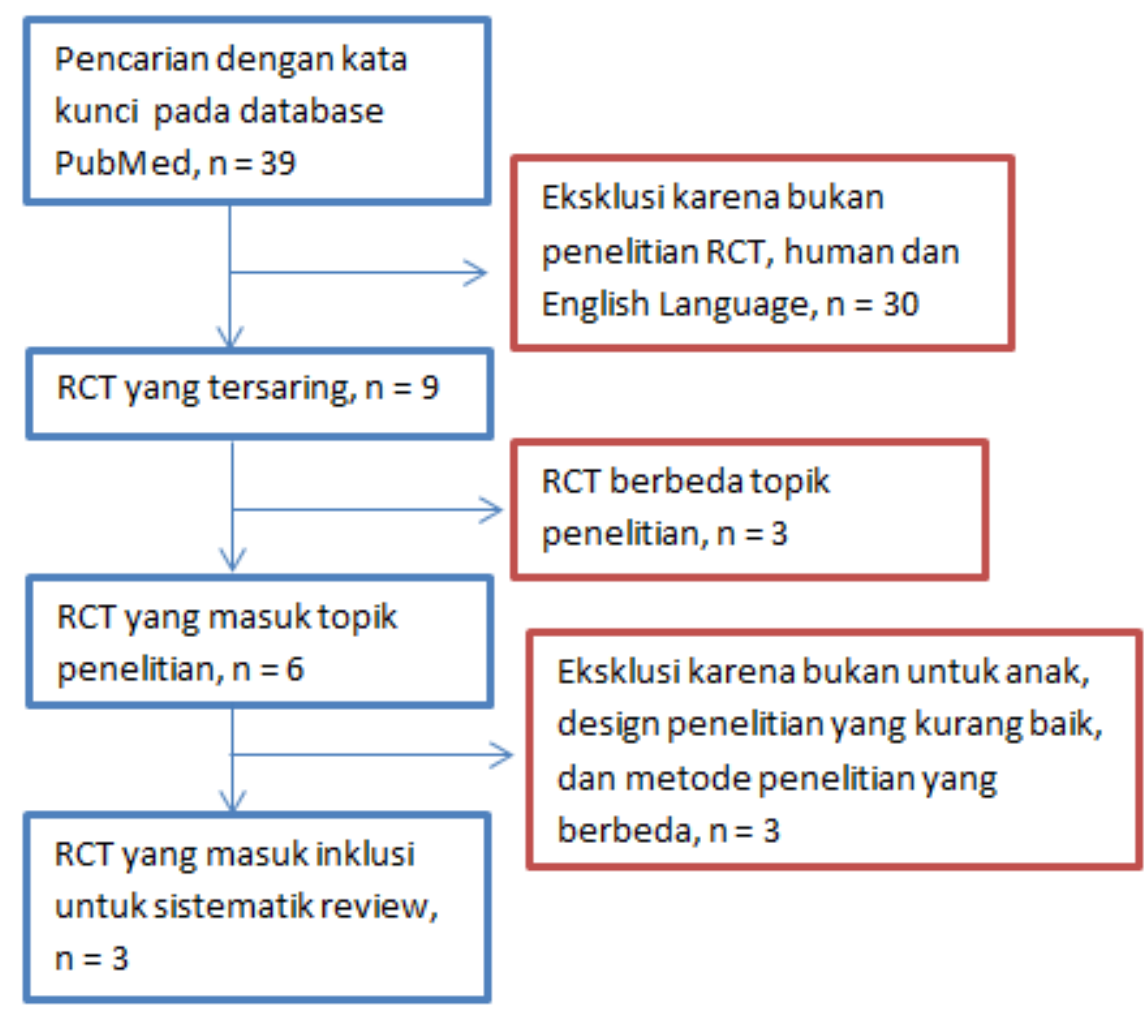

Gambar 1. Diagram kriteria jurnal

\section{HASIL}

Pada pencarian jurnal di database jurnal PubMed didapatkan hasil 9 item jurnal Randomized Controlled Trial yang telah diseleksi dengan filter kunci "human" dan "english language" untuk kemudian ditelaah per-item jurnal yang didapat. Hasil telaah maka didapatkan 6 jurnal yang termasuk dalam topik 
yang dibahas dan 3 jurnal dieksklusi karena diluar topik. Kemudian ditelaah lagi dari 6 jurnal yang dimasukkan sebelumnya, sehingga didapatkan 3 jurnal RCT yang akan dijadikan sumber dalam sistematik review ini. Sedangkan 3 jurnal lainnya diekslusi karena design penelitian kurang baik, tidak untuk pasien anak-anak dan metode penelitian yang berbeda. Sumber penelitian Randomized Controlled Trial yang digunakan untuk sistematik review ini adalah:
1. Gries DM, Moffitt DR, Pulos E, Carter ER (2000).

2. Greenberg RA, Kerby G, Roosevelt GE (2008).

3. Panaigua N, Lopez R, Munoz N, Tames M, Mojica E, Arana-Arri E, Mintegi S, Benito J (2017).

Setelah didapatkan 3 jurnal Randomized Controlled Trial, maka tiga jurnal yang didapat ditelaah karakteristiknya, agar tampak perbandingan antara ketiganya dalam masing masing penelitian (tabel 1).

Tabel 1

Karakteristik Tiap Jurnal yang Digunakan

\begin{tabular}{|c|c|c|c|}
\hline Karakteristik Studi & Gries (2000) & Greenberg (2008) & Panaigua (2017) \\
\hline Jenis Penelitian & RCT & RCT & $\mathrm{RCT}$ \\
\hline Fokus Terapi & Astma pada Pediatri & Astma pada Pediatri & Astma pada Pediatri \\
\hline Jumlah Sampel & 32 pasien & 89 pasien & 557 pasien \\
\hline Kontrol & Prednison oral & Prednison oral & Prednison oral \\
\hline Perlakuan & Deksametason IM & Deksametason oral & Deksametason oral \\
\hline Durasi Penelitian & 28 hari & 10 hari & 15 hari \\
\hline Umur Pasien & 6 bulan -7 tahun & $2-18$ tahun & 12 bulan -14 tahun \\
\hline Tempat Penelitian & Tripler Army Medical & Children's & Tertiary hospital near \\
\hline & $\begin{array}{l}\text { Center, Honolulu, } \\
\text { Hawaii }\end{array}$ & $\begin{array}{l}\text { Hospital, Denver, } \\
\text { Colorado, USA }\end{array}$ & $\begin{array}{l}\text { Bilbao, in the Basque } \\
\text { Country (Spain). }\end{array}$ \\
\hline $\begin{array}{l}\text { Luaran (Outcome) } \\
\text { Penelitian }\end{array}$ & $\begin{array}{l}\text { Pengobatan } \\
\text { eksaserbasi astma akut } \\
\text { dan pencegahan relaps }\end{array}$ & $\begin{array}{l}\text { Pencegahan relaps } \\
\text { pada eksaserbasi astma } \\
\text { akut }\end{array}$ & $\begin{array}{l}\text { Pengobatan } \\
\text { eksaserbasi astma akut } \\
\text { dan pencegahan relaps }\end{array}$ \\
\hline
\end{tabular}

Jurnal RCT yang diambil untuk sistematik review ini kemudian dinilai kualitas metodologinya dengan Jadad's Score. Jadad's Score merupakan salah satu metode untuk menentukan kualitas metode penelitian yang diambil agar dapat ditentukan apakah suatu penelitian layak untuk dimasukkan dalam systematic review. Hasil dari Jadad's Score adalah sebagai berikut:

Tabel 2

Penilaian Jadad's Score

\begin{tabular}{clccc}
\hline No & \multicolumn{1}{c}{ Kriteria } & Gries (2000) & Greenberg (2008) & Panaigua (2017) \\
\hline $\mathbf{1}$ & $\begin{array}{l}\text { Apakah dilakukan } \\
\text { randomisasi? }\end{array}$ & 1 & 1 & 1 \\
$\mathbf{2}$ & $\begin{array}{l}\text { Apakah metode } \\
\text { randomisasi } \\
\text { disebutkan dengan } \\
\text { jelas? } \\
\mathbf{3}\end{array}$ & $\begin{array}{l} \\
\text { Apakah penelitian buta } \\
\text { ganda/double-blind? } \\
\mathbf{4}\end{array}$ & 1 & \\
& $\begin{array}{l}\text { Apakah metode } \\
\text { pembutaan disebutkan } \\
\text { dengan jelas? terdapat } \\
\mathbf{5}\end{array}$ & 1 & 1 & \\
& $\begin{array}{l}\text { Apakah } \\
\text { penjelasan tentang } \\
\text { drop out? }\end{array}$ & 1 & 1 \\
\hline
\end{tabular}




\section{Total skor}

2

4

Gries (2000) meneliti tentang kejadian eksaserbasi asma akut pada anak - anak umur 6 bulan sampai 7 tahun. Hanya pasien dengan asma ringan sampai sedang saja yang dimasukkan dalam penelitiannya. Penelitian ini dilakukan secara randomized, single center namun tidak dijelaskan metode randomisasinya. Sedangkan untuk metode blinding dilakukan hanya pada investigator penelitian. Pasien grup Prednison, diberikan peroral prednison dengan dosis 2 $\mathrm{mg} / \mathrm{kgBB} /$ hari selama 5 hari. Sedangkan pemberian intramuskular deksametason pada grup deksametason disesuaikan dengan umur pasien antara $16 \mathrm{mg}$ sampai dengan $36 \mathrm{mg}$. Kedua grup tetap menerima terapi albuterol tiap 4 sampai 6 jam apabila diperlukan. Dari 33 pasien yang mengikuti penelitian, hanya 1 pasien yang keluar dari penelitian karena mengalami batuk persisten. Sehingga hanya didapatkan 15 pasien untuk Deksametason dan 17 pasien untuk Prednison.

Hasil Penelitian Gries (2000) menyatakan bahwa setelah terapi dengan kortikosteroid selama 5 hari, jumlah sampel yang sembuh total dari asma pada deksametason sebanyak 11 dari 15 pasien (4 pasien masih tampak gejala asma); dan pada prednison sebanyak 11 dari 17 pasien (6 pasien masih tampak gejala asma). Angka kejadian relaps monitoring selama 1 bulan, didapatkan pada grup deksametason sebanyak 1 dari 15 pasien sedangkan pada grup prednison sebanyak 3 dari 17 pasien. Hasil akhir dari penelitian ini menyimpulkan bahwa intramuskular deksametason sama efektifnya dengan peroral prednison untuk manajemen eksaserbasi asma akut ringan sampai dengan sedang pada anak - anak.

Greenberg (2008) meneliti tentang kejadian relaps asma akut pada anak - anak umur 2 tahun sampai dengan 18 tahun. Penelitiannya dilakukan secara prospektif, randomized dan double-blind namun hanya single-center. Penelitian ini melibatkan kejadian eksaserbasi asma akut dari ringan sampai dengan parah dengan alat ukur Pediatric Astma Score rentang 1 sampai dengan 15 . Dari 167 pasien yang akan diikutkan dalam penelitian, hanya 89 pasien yang menyelesaikan terapi sampai selesai dengan alokasi 38 pasien grup prednison dan 51 pasien grup deksametason. Perlakuan dalam penelitian Greenberg (2008), anak - anak yang datang ke emergency department karena eksaserbasi asma akut ringan sampai dengan sedang diintervensi dengan nebulizer albuterol dan ipratropium bromide. Setelah itu, grup deksametason diberikan peroral deksametason dengan dosis $0,6 \mathrm{mg} / \mathrm{kgBB}$ sedangkan grup prednison diberikan peroral prednison $2 \mathrm{mg} / \mathrm{kgBB}$. Penelitian ini juga menggunakan metode double-blinding sehingga kualitas metodologinya cukup baik. Double-blinding dilakukan dengan membuat semua sediaan obat menjadi serbuk yang dimasukkan kedalam kapsul. Tidak ada perbedaan dalam bentuk maupun warna kapsul yang diberikan. Hasil penelitian Greenberg (2008) adalah follow-up pasien setelah monitoring gejala relaps selama 10 hari, maka didapatkan data grup deksametason mengalami relaps sebanyak 8 pasien dari 51 pasien selama 10 hari monitoring. Grup prednison mengalami relaps sebanyak 3 pasien dari 38 pasien selama 10 hari monitoring. Tidak dijelaskan lebih lanjut sebagai simpulan pasien yang tidak mengalami relaps pada grup deksametason dan prednison, apakah perkembangan gejala asmanya sembuh total atau ada kekambuhan walaupun tidak parah. Sebagai kesimpulan dari penelitian oleh Greenberg (2008) yaitu tidak ada perbedaan pada insiden relaps antara perlakuan peroral deksametason dengan peroral prednison.

Panaigua (2017) meneliti tentang perbandingan terapi peroral deksametason dengan prednison untuk pengobatan gejala asma persisten akut anak - anak serta pencegahan relaps terjadi. Penelitian dilakukan secara prospektif, randomized, open-label dan noninferior controlled trial. Metode randomisasi dijelaskan dengan jelas dan baik, namun tidak dilakukan dengan double-blind, hanya data manager dan tim statistik saja yang blind. Penelitian ini juga hanya single-center saja dan hanya melibatkan eksaserbasi asma tingkat ringan hingga sedang. Dari 710 pasien yang akan diikutkan dalam penelitian hanya 590 pasien saja yang bersedia dan mampu diinklusi untuk perlakuan disebabkan karena pasien menolak atau hambatan bahasa. Dari 590 pasien yang diberi perlakuan, dibagi menjadi 2 grup dengan alokasi grup deksametason sebanyak 294 pasien dan grup prednison sebanyak 296 pasien. Dengan hasil akhir hanya 557 pasien saja yang dapat menyelesaikan perlakuan sampai selesai dan 
dapat diambil datanya, dengan alokasi 281 pasien grup deksametason dan 276 pasien grup prednison. Alat ukur eksaserbasi asma menggunakan Pediatric Astma Control Tool / PACT untuk menilai keparahan serangan asma. Outcome primer yang dinilai dalam penelitian Panaigua (2017) adalah persentase pasien yang mengalami gejala asma persisten setelah perlakuan selama 7 hari dan menilai quality of life-nya. Sedangkan outcome sekundernya menilai kejadian relaps (revisit emergency department yang tidak terjadwal), kepatuhan dan kejadian muntah selama 15 hari monitoring terapi. Perlakuan dalam penelitian Panaigua (2017) yaitu pasien anak - anak yang mengalami eksaserbasi asma akut dan datang ke emergency department diterapi berdasarkan protokol terapi untuk asma yaitu anak - anak menerima albuterol inhalasi pada interval 20 menit dan dosis tambahan ipratropium bromide diberikan berdasarkan permintaan dokter atas dasar protokol yang berlaku. Suplemental oksigen tetap diberikan untuk menjaga saturasi oksigen tetap $\geq 93 \%$. Kortikosteroid diberikan selama jam pertama penanganan asma. Pasien dengan grup deksametason menerima peroral deksametason $0,6 \mathrm{mg} / \mathrm{kgBB}$ pertama dan dosis lanjutan pada 24 jam setelahnya. Pasien dengan grup prednison menerima peroral prednison/prednisolon pertama dosis 1,5 $\mathrm{mg} / \mathrm{kgBB}$ di emergency department dan dosis $1 \mathrm{mg} / \mathrm{kgBB} /$ hari dua kali sehari untuk hari ke 2 -5 .

Hasil penelitian Panaigua (2017) adalah berupa outcome primer dan sekunder. Outcome primer berupa persentase pasien yang mengalami gejala asma persisten setelah 7 hari terapi dengan kortikosteroid dan quality of life-nya. Pada grup deksametason didapatkan data pasien yang mengalami gejala asma persisten setelah monitoring terapi selama 7 hari sebanyak 159 pasien dari 281 pasien $(56,6 \%)$ yang diterapi dengan peroral deksametason, sehingga dapat dihitung pasien yang sembuh atau tidak ada gejala persisten asma sebanyak 122 pasien dari 281 pasien. Pada grup prednison didapatkan data pasien yang

\begin{tabular}{|c|c|c|c|c|c|}
\hline \multirow[b]{2}{*}{ Study or Subgroup } & \multicolumn{2}{|c|}{ Deksametason } & \multicolumn{2}{|c|}{ Prednison } & \multirow[b]{2}{*}{ Weight } \\
\hline & Events & Total & Events & Total & \\
\hline Gries 2000 & 4 & 15 & 6 & 17 & $1.8 \%$ \\
\hline Panaigua 2017 & 159 & 281 & 161 & 276 & $98.2 \%$ \\
\hline Total $(95 \% \mathrm{Cl})$ & & 296 & & 293 & $100.0 \%$ \\
\hline Total events & 163 & & 167 & & \\
\hline
\end{tabular}

$$
\text { Risk Ratio }
$$

Test for overall effect: $Z=0.48(P=0.63)$ mengalami gejala asma persisten setelah monitoring terapi selama 7 hari sebanyak 161 pasien dari 276 pasien $(58,3 \%)$ yang diterapi dengan peroral prednison, sehingga dapat dihitung pasien yang sembuh atau tidak ada gejala persisten asma sebanyak 115 pasien dari 276 pasien. Sedangkan nilai quality of life-nya tidak merupakan fokus sistematik review ini. Pada outcome sekunder fokus kepada data relaps / unschedule return to emergency department setelah monitorig terapi selama 15 hari. Grup deksametason mengalami relaps sebanyak 13 pasien dari 281 pasien $(4,6 \%)$, sedangkan grup prednison mengalami relaps sebanyak 9 pasien dari 276 pasien (3,3\%). Dari penelitian Panaigua (2017) dapat disimpulkan bahwa dua dosis deksametason bisa menjadi alternatif atau dengan kata lain sama efektifnya dibandingkan dengan 5 hari terapi prednison/prednisolon untuk gejala eksaserbasi asma akut persisten ringan sampai sedang dan dapat meningkatkan quality of life. Dari ketiga jurnal yang dimasukkan dalam sistematik review ini 2 diantaranya dapat menilai efektifitas kortikosteroid untuk pengobatan atau meredakan gejala eksaserbasi asma akut (penelitian Gries, 2000 dan Panaigua, 2017), sedangkan penelitian Greenberg (2008) tidak dapat diambil data mengenai terapi kuratif atau pengobatan dari kortikosteroid.

Semua jurnal yang dimasukkan dapat diambil data mengenai relaps atau didefinisikan dengan kunjungan ulang ke emergency department yang tidak terjadwal karena kambuhnya asma akut. Sehingga dalam sistematik review ini hanya menganalisis dua variabel yaitu redanya gejala eksaserbasi asma akut dan tidak terjadinya relaps setelah monitoring terapi selama beberapa hari.

Metaanalisis dilakukan dengan software Revman 5.3 untuk menganalisis efektivitas Deksametason versus Prednison untuk pengobatan eksaserbasi asma akut serta pencegahan kejadian relaps pada pasien anak anak, sebagai berikut:

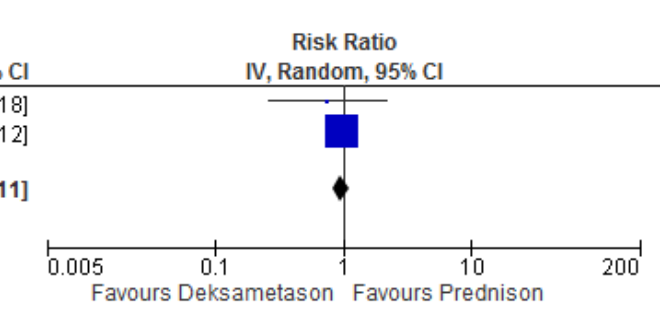

\section{Gambar 2. Perbandingan Efektivitas Deksametason versus Prednison dalam Pengobatan} Eksaserbasi Asma Akut pada Pasien Anak - Anak 
Dari Forest Plot pada gambar 2 dapat diinterpretasikan bahwa Relative Risk total menunjukkan 0,97 yang berarti bahwa perlakuan dengan deksametason lebih poten mengurangi gejala eksaserbasi asma akut pada anak - anak sebesar 3\% relatif dibanding perlakuan dengan prednison, namun hal ini

\begin{tabular}{|c|c|c|c|c|c|}
\hline \multirow[b]{2}{*}{ Study or Subgroup } & \multicolumn{2}{|c|}{ Deksametason } & \multicolumn{2}{|c|}{ Prednison } & \multirow[b]{2}{*}{ Weight } \\
\hline & Events & Total & Events & Total & \\
\hline Greenberg 2008 & 8 & 51 & 3 & 38 & $27.6 \%$ \\
\hline Gries 2000 & 1 & 15 & 3 & 17 & $9.4 \%$ \\
\hline Panaigua 2017 & 13 & 281 & 9 & 276 & $63.0 \%$ \\
\hline Total $(95 \% \mathrm{Cl})$ & & 347 & & 331 & $100.0 \%$ \\
\hline Total events & 22 & & 15 & & \\
\hline
\end{tabular}
Risk Ratio

Random, 95\% C $1.99[0.56,7.00]$ $0.38[0.04,3.26]$

$1.42[0.62,3.27]$

$1.37[0.71,2.66]$

tidak berbeda signifikan secara statistik, karena $\mathrm{p}=0,63 \quad(\mathrm{p}>0,05)$. Data menunjukkan homogenitas yang baik, dimana nilai $\mathrm{I} 2=0 \%$. Sehingga dapat disimpulkan bahwa Deksametason sama efektifnya dibanding dengan Prednison dalam mengurangi gejala eksaserbasi asma akut pada anak - anak.

\begin{tabular}{|c|c|c|} 
Risk Ratio \\
IV, Random, $95 \% \mathrm{Cl}$
\end{tabular}

\section{Gambar 3. Perbandingan Efektivitas Deksametason versus Prednison dalam Merurunkan Angka Pasien Relaps Asma Akut pada Anak - Anak}

Dari Forest Plot diatas dapat diinterpretasikan bahwa Relative Risk Total sebesar 1,37 namun Diamond masih menyentuh garis tengah. Hal ini dapat diinterpretasikan bahwa perlakuan dengan Prednison lebih poten dalam menurunkan angka pasien relaps asma akut pada anak - anak sebesar 37\% relatif dibandingkan dengan Deksametason, namun hal ini masih tidak berbeda signifikan secara statistik, karena $p=0,35 \quad(p>0,05)$. Data menunjukkan homogenitas yang baik dimana nilai $I 2=0 \%$. Sehingga dapat disimpulkan bahwa Prednison sama efektifnya dibandingkan dengan Deksametason dalam menurunkan angka relaps eksaserbasi asma akut pada pasien anak - anak.

\section{PEMBAHASAN}

Asma adalah salah satu penyakit kronis yang sering dijumpai di seluruh dunia dan diperkirakan 300 juta orang terkena penyakit ini. Tujuan terapi utama asma yaitu meningkatkan dan mempertahankan kualitas hidup pasien asma sehingga pasien dapat melakukan aktivitas sehari - hari tanpa hambatan berarti (Direktorat Bina Farmasi Komunitas dan Klinis, 2007).

Prevalensi meningkat di beberapa negara, khususnya pada anak - anak. Asma adalah alasan utama ketidakhadiran di sekolah dan pekerjaan (GINA, 2015). Asma tidak hanya mempengaruhi kualitas hidup pasien, tapi juga keluarga pasien, produktivitas pasien, ketidakhadiran di sekolah, peningkatan biaya kesehatan, risiko perawatan di rumah sakit dan bahkan kematian (CDC, 2013). Asma termasuk dalam jajaran penyakit tidak menular peringkat sepuluh besar penyebab pasien menjalanirawat inap di rumah sakit di Indonesia berdasarkan Pusat Data dan Informasi Kementerian Kesehatan Republik Indonesia (2012).

Inhaled Corticosteroids merupakan pengontrol serangan asma. Kortikosteroid bukan termasuk reliever atau pereda serangan asma berdasarkan GINA (2015). Pereda serangan asma berdasarkan GINA (2015) yaitu SABA (Short Acting Beta Agonist) seperti albuterol. Bisa ditambahkan SAMA (Short Acting Muscarinic Antagonist) seperti Ipratropium Bromide untuk mengadisi efek relaksan otot bronkus. Setelah itu, kortikosteroid ditambahkan untuk mengontrol atau menjaga agar asma tidak kambuh lagi atau meminimalisir frekuensi kekambuhan ulang. Kortikosteroid sistemik diindikasikan untuk semua pasien asma akut parah yang tidak mengalami perbaikan setelah pemberian inhalasi beta 2 adrenergik (PDPI, 2003).

Dalam 3 jurnal yang didapat, perlakuan para peneliti dalam terapi kekambuhan asma akut pada anak - anak sudah sesuai dengan guideline atau protokol yang ada. Sebagian besar terapi awal yaitu menggunakan inhaler albuterol yang ditambahkan ipratropium bromide dengan saturasi oksigen. Kemudian dilanjutkan dengan pemberian kortikosteroid baik secara peroral maupun parenteral untuk pemeliharaan eksaserbasi asma.

Semua jurnal penelitian menggunakan kriteria inklusi eksklusi dalam penelitiannya. Diantara kriteria inklusi yaitu rentang umur anak tertentu, pasien anak - anak yang datang ke emergency department dengan keluhan eksaserbasi asma akut, kategori asma ringan sampai dengan sedang, namun penelitian oleh Greenberg (2008) masih memasukkan pasien dengan asma akut kategori berat dalam sampel 
penelitiannya. Sedangkan untuk kriteria eksklusi diantaranya menggunakan oral steroid pada bulan yang lalu, histori intubasi untuk eksaserbasi asma, adanya penyakit paru kronis yang bisa mempengaruhi hasil penelitian dan lain sebagainya.

Dari hasil metaanalisis 3 jurnal yang digunakan, dengan perangkat software Revman 5.3, kami menganalisa efektivitas penggunaan deksametason dan prednison untuk mengurangi gejala eksaserbasi asma akut dan juga menurunkan angka relaps pasien anak - anak. Hasil perbandingan efektivitas deksametason versus prednison untuk mengurangi gejala eksaserbasi asma akut pada pasien anak - anak didapatkan bahwa deksametason sedikit lebih poten dibandingkan prednison, namun tidak berbeda signifikan secara statistik. Sehingga tetap disimpulkan bahwa deksametason sama efektifnya dengan prednison dalam mengurangi gejala eksaserbasi asma akut pada pasien anak - anak. Penelitian oleh Panaigua (2017) mempunyai kontribusi besar dalam metaanalisis ini karena besarnya jumlah sampel yang diberikan dibandingkan 2 penelitian lainnya.

Hasil perbandingan efektivitas deksametason versus prednison untuk menurunkan angka relaps asma akut pada pasien anak - anak didapatkan bahwa prednison sedikit lebih poten dibandingkan deksametason, namun tidak berbeda signifikan secara statistik. Sehingga tetap disimpulkan bahwa deksametason sama efektifnya dengan prednison dalam menurunkan angka relaps asma akut pada pasien anak - anak. Penelitian oleh Panaigua (2017) mempunyai kontribusi besar dalam metaanalisis ini karena besarnya jumlah sampel yang diberikan dibandingkan 2 penelitian lainnya.

Dari telaah kualitas jurnal yang didapat melalui Jadad's Score, diketahui bahwa penelitian Randomized Controlled Trial oleh Gries (2000) mempunyai skor Jadad yang kurang yaitu 2. Hal ini disebabkan karena dalam telaah yang sudah kami lakukan diketahui bahwa metode randomisasi tidak dipaparkan dengan jelas dan tidak adanya blinding sehingga mengurangi kualitasnya sebagai penelitian Randomized Controlled Trial. Namun tetap dipaparkan oleh Gries bahwa penelitian mereka adalah randomized. Selain itu juga dijelaskan jumlah peserta uji yang keluar / dropout dari jalannya penelitian.

Penelitian Randomized Controlled Trial oleh Greenberg (2008) mempunyai skor Jadad yang baik yaitu 4. Hal ini didukung oleh adanya randomisasi dan double-binding. Dijelaskan pula metode untuk double-blinding dengan jelas dan sesuai. Jumlah peserta penelitian yang keluar / dropout juga dijelaskan beserta alasan keluarnya. Kelemahannya hanya tidak dijelaskan secara rinci metode randomisasi penelitian sehingga mengurangi kualitasnya sebagai penelitian Randomized Controlled Trial. Namun secara keseluruhan, penelitian Greenberg (2008) mempunyai kualitas yang baik.

Penelitian Randomized Controlled Trial oleh Panaigua (2017) mempunyai skor Jadad yang baik yaitu 3 . Hal ini didukung oleh adanya metode randomisasi yang dijelaskan perinciannya serta penjelasan jumlah peserta yang keluar / dropout beserta alasannya. Kelemahan penelitian oleh Panaigua (2017) ini yaitu karena tidak dilakukan double-blinding sehingga termasuk open-label.

Keterbatasan dalam sistematik review ini diantaranya variabilitas sampel dengan mengambil pasien anak - anak dengan berbagai umur. Hal ini sulit untuk dihindari mengingat para peneliti menggunakan kriteria sendiri untuk menentukan umur sampelnya. Selain umur pasien, alat ukur untuk penentuan eksaserbasi asma juga bervariasi. Namun hampir kesemuanya menggunakan alat ukur yang sudah tervalidasi. Perbedaan tempat penelitian juga mungkin mempunyai pengaruh pada hasil penelitian, dimana penelitian oleh Greenberg (2008) dilakukan diketinggian 5280 kaki, cukup tinggi untuk mempengaruhi variabel penelitian.

Semua penelitian dilakukan secara singlecenter atau terpusat pada satu fasilitas kesehatan saja. Sehingga juga membatasi dalam level of evidence. Dilihat dari banyaknya jumlah sampel, penelitian oleh Panaigua (2017) mempunyai jumlah sampel terbanyak yaitu 557 pasien anak - anak sehingga sangat mempengaruhi hasil dalam meta analisis. Diikuti oleh penelitian oleh Greenberg (2008) dengan 89 pasien anak - anak dan Gries (2000) dengan 32 pasien anak - anak. Limitasi diatas dapat mempengaruhi bias hasil penelitian.

\section{SIMPULAN DAN \\ SARAN}

Simpulan

Evidence yang tersedia mendukung kesimpulan bahwa penggunaan Deksametason sama efektifnya dengan Prednison dalam mengurangi gejala eksaserbasi asma akut serta 
menurunkan angka relaps pada pasien anak anak.

\section{Saran}

Peneliti selanjutnya diharapkan mendapatkan data penelitian dengan sumber penelitian lainnya.

\section{DAFTAR PUSTAKA}

CDC. 2013. Astma facts-CDC's National Astma Control Program Grantees. Atlanta.

Direktorat Bina Farmasi Komunitas dan Klinis. 2007. Pharmaceutical Care untuk Penyakit Asma. Departemen Kesehatan Republik Indonesia. Jakarta.

Gillisen A. 2007. Patient's adherence in asthma. $J$ Physiol Pharmacol. 58:205-222.

GINA. 2015. Global Srategy for Astma Management and Prevention. Global Initiative for Astma.

Greenberg RA, Kerby G, Roosevelt GE. 2008. A Comparison of Oral Dexamethasone With Oral Prednisone in Pediatric Asthma Exacerbations Treated in the Emergency Department. Clin. Pediatr. 47: 817. doi: 10.1177/0009922808316988

Gries DM, Moffitt DR, Pulos E, Carter ER. 2000. A single dose of intramuscularly administered dexamethasone acetate is as effective as oral prednisone to treat asthma exacerbations in young children. $J$. Pediatr. 136:298-303

Hasselgren M, Arne M, Lindahl A, Janson S, Lundback B. 2001. Estimated prevalences of respiratory symptoms, astma and chronic obstructive pulmonary disease related to detection rate in primary healthcare. Scan $J$ Prim Heatlh Care. 19:54-57.

Kelly, HW dan Sorkness, CA. 2008. Astma, dalam Dipiro JT Robert L, Gary RM,
Barbara GW, Michael P. Pharmacotheapy a Pathophysiologic Approach 7 Ed. Appleton dan Lange. Connecticut. Halaman 463 - 493.

Masoli M, Fabian D, Holt S, et al. 2004. The global burden of asthma: executive summary of the GINA Dissemination Committee Report. Allergy. 59:469-78.

Nugroho AE. 2012. Farmakologi : Obat Obat Penting dalam Pembelajaran Ilmu Farmasi dan Dunia Kesehatan. Pustaka Pelajar. Yogyakarta. Halaman 184 - 186.

O. Stefan, T. Martina, D. G. Romy, G. Fabienne, S. Fong, W. Michel, et al. 2013. Pharmacist-led intervention study to improve drug therapy in asthma and COPD patients. Int J Clin Pharm. 1096-013-9887-4.

Panaigua N, Lopez R, Munoz N, Tames M, Mojica E, Arana-Arri E, Mintegi S, Benito J. 2017. Randomized Trial of Dexamethasone Versus Prednisone for Children with Acute Asthma Exacerbations. J. Pediatr. 191:190-6. https://doi.org10.1016/j.jpeds.2017.0 8.030

Perhimpunan Dokter Paru Indonesia. 2003. Pedoman Diagnosis dan Penatalaksanaan Asma di Indonesia. PDPI. Jakarta.

Pusat Data dan Informasi Kementerian Kesehatan Republik Indonesia. 2012. Gambaran Penyakit Tidak Menular di Rumah Sakit Indonesia Tahun 2009 dan 2010, Kementerian Kesehatan Republik Indonesia, Jakarta.

Rabe KF, Vermeire PA, Soriano JB, Maier WC. 2013. Clinical management of asthma in 1999: the Asthma Insights and Reality in Europe (AIRE) study. Eur Respir J. 16: 802-807. 